\title{
An obligatory role for club cells in preventing obliterative bronchiolitis in lung transplants
}

\author{
Zhiyi Liu, ${ }^{1,2}$ Fuyi Liao, ${ }^{1}$ Davide Scozzi, ${ }^{1}$ Yuka Furuya, ${ }^{3}$ Kaitlyn N. Pugh, ${ }^{1}$ Ramsey Hachem, ${ }^{3}$ \\ Delphine L. Chen, ${ }^{4}$ Marlene Cano, ${ }^{3}$ Jonathan M. Green, ${ }^{3,5}$ Alexander S. Krupnick, ${ }^{6}$ Daniel Kreisel, ${ }^{1,2}$ \\ Anne Karina T. Perl, ${ }^{7,8}$ Howard J. Huang, ${ }^{9}$ Steven L. Brody, ${ }^{3}$ and Andrew E. Gelman ${ }^{1,5}$ \\ 'Department of Surgery, Washington University School of Medicine, St. Louis, Missouri, USA. ${ }^{2}$ Department of Thoracic \\ Surgery, Shanghai Pulmonary Hospital, School of Medicine, Tongji University, Shanghai, China. ${ }^{3}$ Department of Medicine, \\ ${ }^{4}$ Department of Radiology, and ${ }^{5}$ Department of Pathology \& Immunology, Washington University School of Medicine, \\ St. Louis, Missouri, USA. 'Department of Surgery, University of Virginia School of Medicine, Charlottesville, Virginia, USA \\ ${ }^{7}$ Department of Pediatrics, University of Cincinnati College of Medicine, Cincinnati, Ohio, USA. ${ }^{8}$ Division of Pulmonary \\ Biology, Cincinnati Children's Hospital Medical Center, Cincinnati, Ohio, USA. ${ }^{9}$ Houston Methodist J.C. Walter Jr. Transplant \\ Center, Houston, Texas, USA.
}

Obliterative bronchiolitis $(\mathrm{OB})$ is a poorly understood airway disease characterized by the generation of fibrotic bronchiolar occlusions. In the lung transplant setting, $\mathrm{OB}$ is a pathological manifestation of bronchiolitis obliterans syndrome (BOS), which is a major impediment to long-term recipient survival. Club cells play a key role in bronchiolar epithelial repair, but whether they promote lung transplant tolerance through preventing $\mathrm{OB}$ remains unclear. We determined if $\mathrm{OB}$ occurs in mouse orthotopic lung transplants following conditional transgene-targeted club cell depletion. In syngeneic lung transplants club cell depletion leads to transient epithelial injury followed by rapid club cell-mediated repair. In contrast, allogeneic lung transplants develop severe $\mathrm{OB}$ lesions that are largely devoid of club cells despite immunosuppression treatment. Lung allograft club cell ablation also triggers the recognition of alloantigens, and pulmonary restricted self-antigens reported associated with $\mathrm{BOS}$ development. However, $\mathrm{CD8}{ }^{+} \mathrm{T}$ cell depletion restores club cell reparative responses and prevents $\mathrm{OB}$. In addition, ex vivo analysis reveals a specific role for alloantigenprimed CD8 ${ }^{+} \mathrm{T}$ cells in inhibiting club cell proliferation and maintenance. Taken together, our results demonstrate a vital role for club cells in maintaining lung transplant tolerance and propose a model to identify the underlying mechanisms of $\mathrm{OB}$.

Conflict of interest: The authors have declared that no conflict of interest exists.

Copyright: () 2019 American Society for Clinical Investigation

Submitted: September 10, 2018 Accepted: March 27, 2019 Published: April 16, 2019.

Reference information: /CI Insight. 2019;4(9):e124732. https://doi. org/10.1172/jci.insight.124732.

\section{Introduction}

For over 3 decades lung transplantation has remained the only viable option for many types of end-stage pulmonary diseases. Despite advances in surgical and postoperative management techniques the medium survival after lung transplant significantly lags behind other solid-organ recipients at approximately 5.8 years (1). A major limitation to recipient survival is bronchiolitis obliterans syndrome (BOS), the most common form of chronic lung allograft dysfunction (CLAD) (2). BOS is diagnosed by the loss of forced expiratory volume to the exclusion of other causes of pulmonary dysfunction such as infection, acute rejection, or anastomotic complications. BOS severity is driven by the progression of obliterans bronchiolitis $(\mathrm{OB})$, inflammatory fibrotic eruptions that partially or completely obstruct the distal bronchioles (1).

Club cells are nonciliated epithelial secretory cells that are highly prevalent in the pulmonary distal bronchioles in both humans and mice (3). They are often identified by the expression of Scgb1a1, which encodes the club cell secretory protein (CCSP, CC10), a $16-\mathrm{kDa}$ peptide with reported antiinflammatory properties that coats airway surfaces (4). Club cells help maintain small airway homeostasis through detoxifying xenobiotic and oxidizing molecules, secretion of antimicrobial peptides, and promotion of mucociliary clearance. They also play a key role in bronchiolar epithelial repair through their ability to self-renew and differentiate into ciliated and goblet cells (5). In line with these observations, several studies have shown that targeted club cell ablation delays or prevents epithelial repair $(6,7)$. Interestingly, many nonalloimmune stressors of airway 
epithelium are risk factors for BOS development, which include primary graft dysfunction (8), Pseudomonas aeruginosa infection (9), community-acquired respiratory viral infections (10), and chronic aspiration of gastric acid $(11,12)$. There are also a few reports demonstrating club cell injury in lungs with BOS. For example, low CCSP levels in bronchiolar lavage fluid have been reported either as a risk factor for, or associated with, BOS development $(13,14)$. More recently, Palmer and colleagues demonstrated that patients with BOS have diminished CCSP expression in the airway epithelial cells of their terminal bronchioles (15). However, it remains to be investigated whether club cell loss is sufficient to trigger OB pathogenesis and promote immune responses known to be associated with BOS risk.

Here, we describe a mouse orthotopic lung transplant (OLT) model that generates OB lesions in response to bronchiolar epithelial injury generated through the conditional activation of transgenes that direct club cell ablation. Club cell loss leads to the augmentation of adaptive immune responses that are coupled to BOS risk. Additionally, we find that $\mathrm{CD}^{+} \mathrm{T}$ cells play an important role in inhibiting club cell maintenance and proliferation.

\section{Results}

Club cell ablation triggers $O B$ pathogenesis in lung transplant allografts. To determine if the loss of club cells promotes $\mathrm{OB}$, we utilized triple-transgenic (3T) mice bearing the following genes: a reverse tetracycline activator gene driven by the CCSP promoter, Cre recombinase gene under control of the reverse tetracycline activator, and a lox- $P$-activated diphtheria toxin A gene (DT-A). Ingestion of doxycycline by $3 \mathrm{~T}$ mice induces $C r e$-mediated recombination of the lox-P DT-A locus that promotes DT expression specifically in CSSP-expressing cells, resulting in their depletion and consequential injury to the bronchiolar epithelium (6). Because $3 \mathrm{~T}$ mice were originally developed on a mixed histocompatibility antigen background, we extensively backcrossed these mice with FVB and C57BL/6 (B6) mice to generate fully defined minor and major histocompatibility 3T FVB and 3T B6 strains for syngeneic and allogeneic transplantation. To induce allograft acceptance in 3T FVB $\rightarrow$ B6 lung recipients, we administered CD40L-neuralizing (CD40L is also known as CD154) antibodies (Abs) and the CD80/86 antagonist CTLA4Ig (Figure 1A), which we have previously demonstrated induces established tolerance in the mouse OLT model 3 days after transplant (16). To implement club cell depletion, 3T B6 $\rightarrow$ B6 (syngeneic) and 3T FVB $\rightarrow$ B6 (allogeneic) recipient mice ingested doxycycline between postoperative day (POD) 7 and POD 9.5. Immunohistochemical analysis of syngeneic and allogeneic transplants on POD 11 revealed small airways denuded of $\mathrm{CCSP}^{+}$cells, but with the preservation of cells that expressed acetylated $\alpha$-tubulin (Ac-tubulin), a marker for ciliated cells (Figure 1, B and C). By POD 16, however, syngeneic recipients had repaired their bronchiolar epithelium, as evident by reconstituted club and ciliated cell luminal monolayers that resembled preinjured bronchioles. In contrast, allografts contained club cells predominantly arranged in nonluminal monolayers without intervening ciliated cells. Additionally, many bronchioles had sharply reduced or completely absent luminal expression of Ac-tubulin, although scattered ciliated cells could be detected throughout the interstitium (Supplemental Figure 1; supplemental material available online with this article; https://doi.org/10.1172/ jci.insight.124732DS1). Histological assessment of POD 16, 3T FVB $\rightarrow$ B6 recipients that underwent club cell ablation revealed high-grade inflammatory bronchiolar injury and severe obliterative disease (Figure 2, A-C). In contrast, analogously treated syngeneic lung transplants had at most mild graft inflammation, and lacked OB or peribronchial lesions up to POD 30 (Supplemental Figure 2). Total collagen deposition, which can be assessed by hydroxyproline assay or visualized by Masson's trichrome stain, is promoted by chronic airway injury and accumulates to a higher degree in BOS patients when compared with stable lung recipients (17). Hydroxyproline accumulation was significantly greater in allografts with OB when compared with syngeneic transplants that underwent club cell ablation (Figure 2D). Masson's trichrome staining of allograft $\mathrm{OB}$ lesions also revealed collagen deposition within transluminal fibrotic lesions (Figure $2 \mathrm{E}$ ). Finally, we did not observe the generation of OB lesions in allograft recipients following treatment with naphthalene (Supplemental Figure 3), an agent that has been used to ablate club cells (18) but may possibly inhibit lymphocyte activation (19)

Previous work has demonstrated that club cells can be defined as pulmonary-restricted CD45-CD34$\mathrm{CD} 1^{-} \mathrm{EpCAM}^{\mathrm{hi}} \mathrm{CCSP}^{\mathrm{hi}}$ cells (20). To further define the dynamics of bronchiolar epithelial repair in lung transplants we performed flow cytometric analysis to quantitate club cell abundance and proliferative responses following injury (Figure 3, A-H). In both syngeneic grafts and allografts there was an approximate $80 \%$ reduction in club cell abundance when measured 1.5 days after ablation. However, within the 


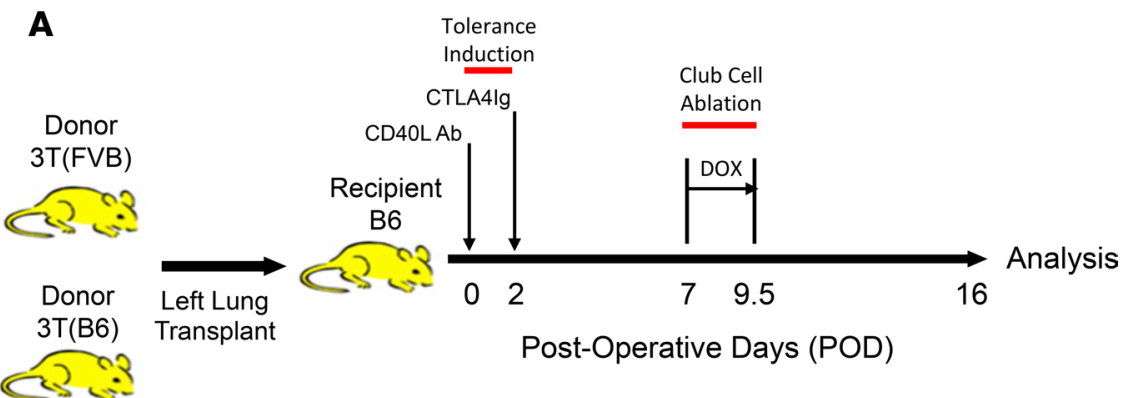

B

Prior to Transplant

C
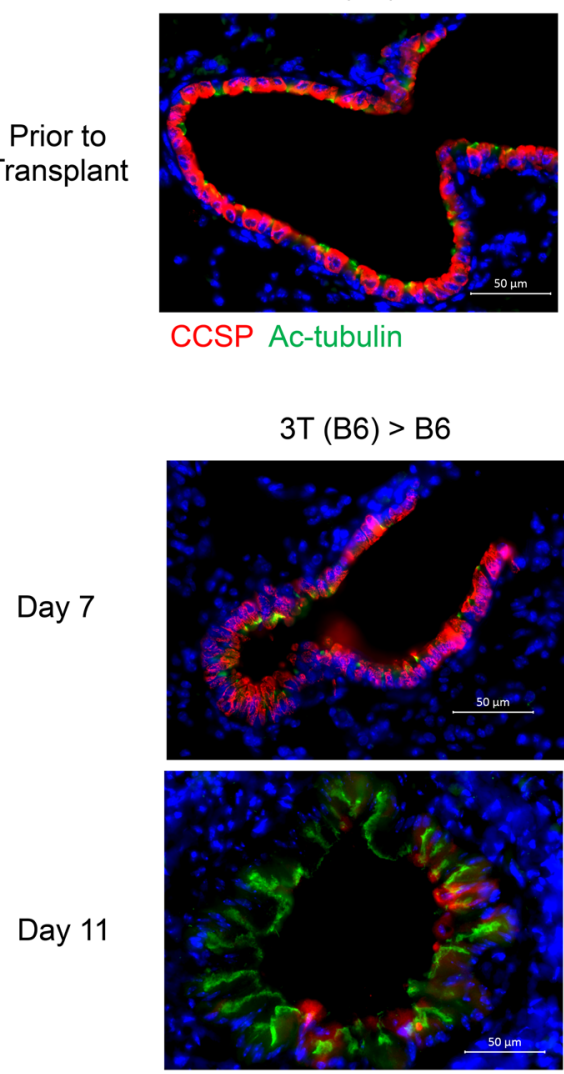

CCSP Ac-tubulin

$3 \mathrm{~T}(\mathrm{~B} 6)>\mathrm{B} 6$

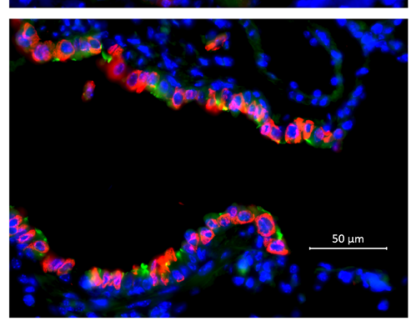

CCSP Ac-tubulin

Day 16
3T(FVB)

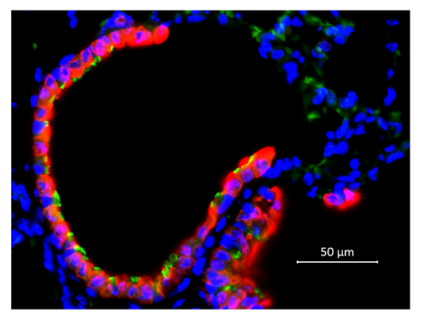

$3 T(F \vee B)>B 6$
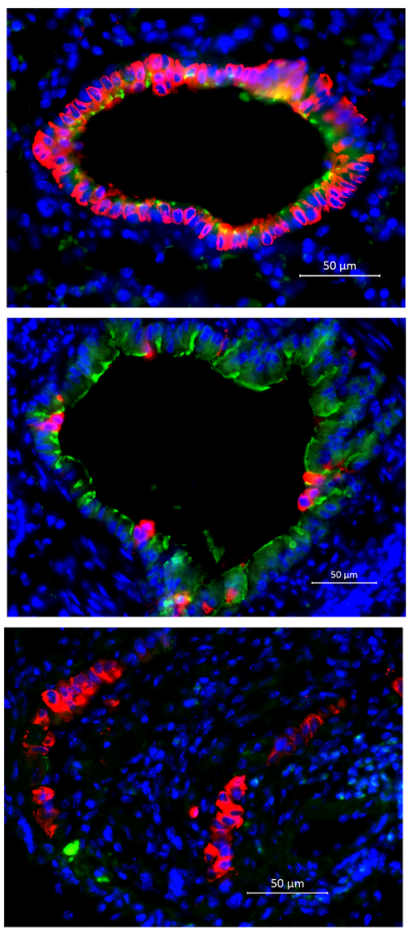

Figure 1. Lung allograft recipients are unable to repair their bronchiolar epithelium following club cell depletion. (A) A mouse OLT model that generates OB in 16 days. B6 recipients of 3T FVB left lungs treated with CD4OL Abs (POD 0) and CTLA4Ig (POD 2) to establish tolerance were fed doxycycline by food and water (DOX) from POD 7 to 9.5 and analyzed for graft inflammation on POD 16. 3T FVB and 3T B6 (B) donor lungs and (C) transplants stained with CCSP and Ac-tubulin Abs on POD 7, 11, and 16. Scale bars: $50 \mu \mathrm{m}$. Data shown are a representative result from at least 3 independent experiments. 
remaining club cell compartment, the number undergoing replication was several-fold higher in syngeneic grafts when compared with allografts. Additionally, on POD 16, syngeneic grafts had nearly 3-fold more club cells relative to allografts. Therefore, club cell regenerative responses are sharply blunted in lung allografts that develop OB.

Club cell ablation stimulates adaptive immune responses to lung transplants. We next determined if club cell depletion leads to a loss of immune tolerance. To this end, we compared effector $\mathrm{T}$ cell responses in $3 \mathrm{~T}$ FVB allografts to double-transgene (2T FVB) allografts that lack the lox-P-activatable DT-A gene and therefore do not develop OB (Supplemental Figure 4). 3T and 2T FVB allograft recipients had comparable numbers of intragraft $\mathrm{CD} 4^{+} \mathrm{T}$ cells, Foxp $3^{+} \mathrm{CD}^{+}$, and IFN- $\gamma^{+} \mathrm{CD} 4^{+} \mathrm{T}$ cells on POD 16 (Figure 4, A and B). However, club cell ablation led to greater accumulation of $\mathrm{IL}-17 \mathrm{~A}^{+} \mathrm{CD} 4^{+}$, total $\mathrm{CD} 8^{+}$, and $\mathrm{IFN}-\gamma^{+} \mathrm{CD} 8^{+} \mathrm{T}$ cells within 3T FVB allografts. Additionally, specifically within airspaces of 3T FVB allografts, there was greater than a 3 -fold increase of IFN- $\gamma^{+} \mathrm{CD}^{+} \mathrm{T}$ cells (Figure 4C). The development de novo donor-antigen-specific Abs (DSAs) is a reported risk factor for BOS development (21). We therefore asked if club cell ablation promotes the accumulation of Abs that recognize FVB antigens (Figure 4D). When compared with recipients of $2 \mathrm{~T}$ FVB allografts, there were significantly greater amounts of DSA against FVB antigens in the peripheral blood of 3T FVB allograft recipients.

Because BOS progression is reportedly coupled to the loss of tolerance to alloantigens and the pulmonary self-restricted antigens, collagen V (ColV) and K- $\alpha 1$ tubulin (Ka1T) (22-24), we next assessed T cell antigen specificity through performing antigen recall assays on $\mathrm{CD}^{+}$and $\mathrm{CD} 8^{+} \mathrm{T}$ cells isolated from $\mathrm{POD}$ 16 lung transplants (Figure 5A). Challenge of 3T FVB allograft CD4+ $\mathrm{T}$ cells with donor antigen-presenting cells (APCs) generated significantly higher amounts of IL-17A but not IFN- $\gamma$ production relative to CD4 ${ }^{+}$ $\mathrm{T}$ cells from $2 \mathrm{~T}$ FVB allografts. Syngeneic APCs bearing ColV or K $\alpha 1 \mathrm{~T}$ peptides also stimulated higher amounts of IL-17A from 3T FVB allograft CD4 ${ }^{+} \mathrm{T}$ cells compared with those from $2 \mathrm{~T}$ FVB allograft $\mathrm{CD}^{+} \mathrm{T}$ cells. Despite the lack of overall expansion of intragraft IFN- $\gamma{ }^{+} \mathrm{CD} 4^{+} \mathrm{T}$ cells there was a small but significant augmentation of IFN- $\gamma$ production following ColV stimulation. In addition, club cell ablation led to more IFN- $\gamma$ production from $3 \mathrm{~T} \mathrm{FVB}$ allograft $\mathrm{CD}^{+} \mathrm{T}$ cells following stimulation with donor antigens or self-antigens. In line with these observations, allografts with $\mathrm{OB}$ had accumulated higher intragraft ColV mRNA and protein along the epithelial basement membrane and within OB lesions (Figure 5, B-D). Together, these results demonstrate that club cell depletion induces the loss of tolerance to donor and pulmonary self-restricted antigens in lung transplants.

Alloantigen-primed $C D 8^{+} T$ cells inhibit club cell regenerative responses. T cells are required for lung allograft rejection (25), but whether they regulate reparative responses by club cells remains unknown. Accordingly, we examined the role of $\mathrm{T}$ cells in our $\mathrm{OB}$ model by utilizing Ab-mediated T cell depletion (Figure 6, A-C, and Supplemental Figure 5). Pan-T cell depletion greatly reduced epithelial inflammation and eliminated OB lesions in 5 out of 7 allografts. Pan-T cell depletion also resulted in the repopulation of bronchiolar epithelium with club and ciliated cells (Figure 6D). Additionally, club cell proliferative responses were sharply elevated over recipients that received control Abs (Figure 6, E and F). Because we observed the high accumulation of airspace-resident effector $\mathrm{CD} 8^{+} \mathrm{T}$ cells in lung allografts with $\mathrm{OB}$ we next tested the effects of $\mathrm{CD} 8$-depleting $\mathrm{Ab}$ administration to recipients (Figure 7, $\mathrm{A}-\mathrm{F}$ ). Like pan-T cell depletion, $\mathrm{CD}^{+} \mathrm{T}$ cell depletion improved club cell regenerative responses and prevented $\mathrm{OB}$ lesion generation. In contrast, $\mathrm{OB}$ development was unaffected by Ab-mediated $\mathrm{CD} 4^{+} \mathrm{T}$ cell depletion (Supplemental Figure 6). To further examine the effects of $\mathrm{CD}^{+} \mathrm{T}$ cells on epithelial injury we cocultured club cells with alloantigen-primed, unprimed allogeneic, or syngeneic $\mathrm{CD}^{+} \mathrm{T}$ cells (Figure $8, \mathrm{~A}-\mathrm{C}$ ). Only alloantigen-primed $\mathrm{CD} 8^{+} \mathrm{T}$ cells inhibited club cell proliferation and maintenance. Noting our previous observations that apical surface MHC class I expression on airway epithelial cells is recognized by allogeneic $\mathrm{CD} 8^{+} \mathrm{T}$ cells (26), we asked if a neutralizing $\mathrm{Ab}$ that recognizes 1 of $3 \mathrm{MHC}$ class I alleles $\left(\mathrm{H}-2 \mathrm{~K}^{\mathrm{q}}\right)$ expressed by FVB mice (27) prevents $\mathrm{CD}^{+} \mathrm{T}$ cell-mediated inhibition of club cell maintenance (Figure $8 \mathrm{D}$ ). Blockade of $\mathrm{H}-2 \mathrm{~K}^{\mathrm{q}}$ significantly improved club cell maintenance, indicating that direct interactions between airway-infiltrating $\mathrm{CD}^{+} \mathrm{T}$ cells and club cells prevent bronchial epithelial repair in lung allografts.

\section{Discussion}

In the model of mouse orthotopic lung allograft transplantation reported in this study, we show that acute epithelial injury mediated by the ablation of club cells is sufficient to cause OB. The depletion and regeneration of the club cell compartment was assessed by immunohistochemistry and flow cytometric analysis. 
A
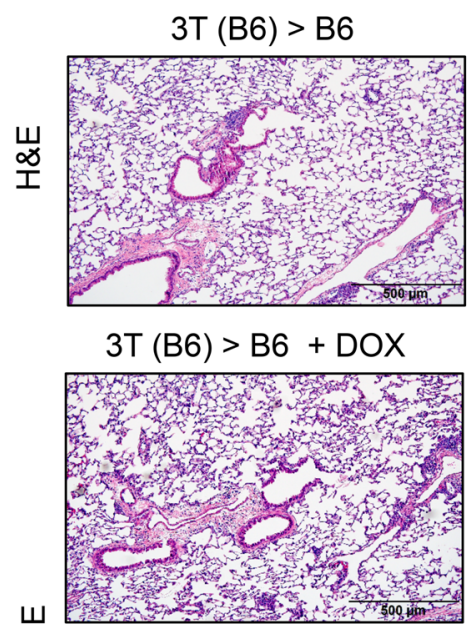

$\underset{\varpi}{\varpi}$
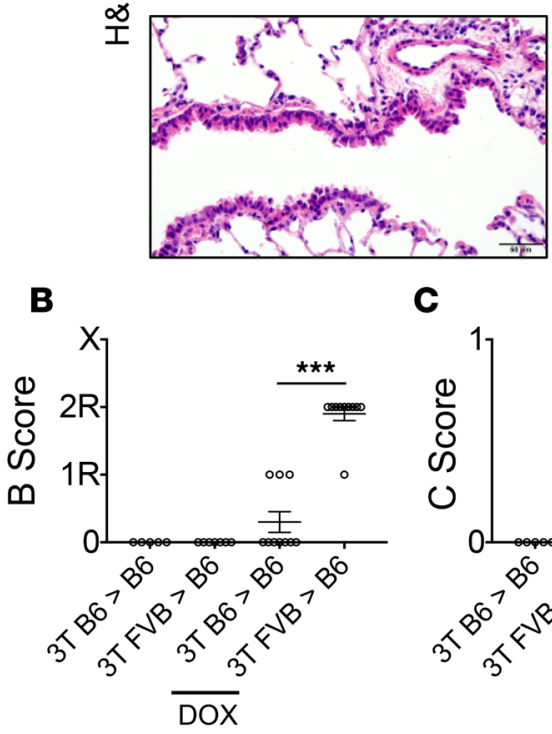

C

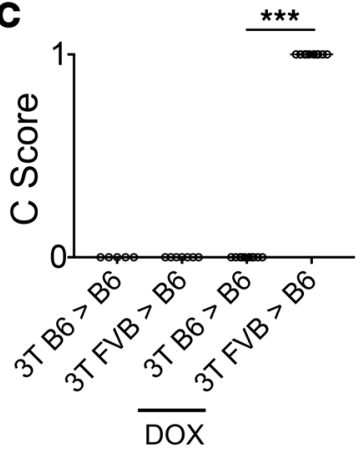

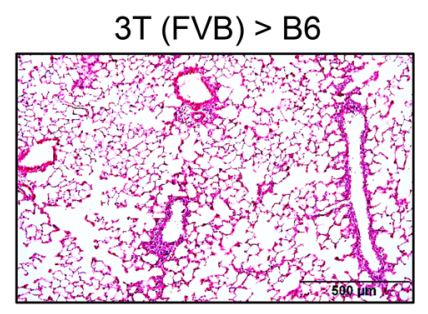

$3 T(F V B)>B 6+D O X$
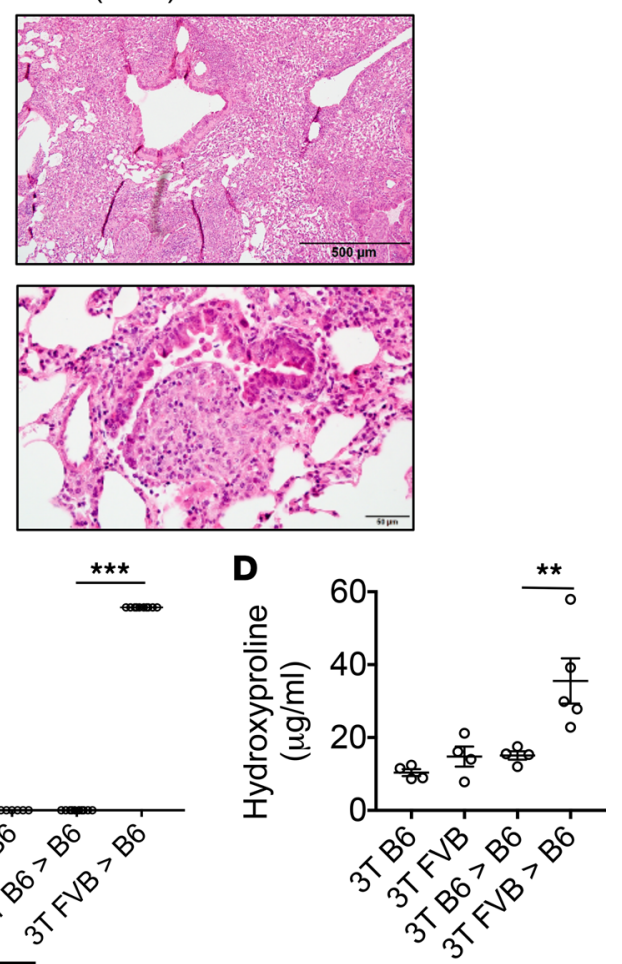

E
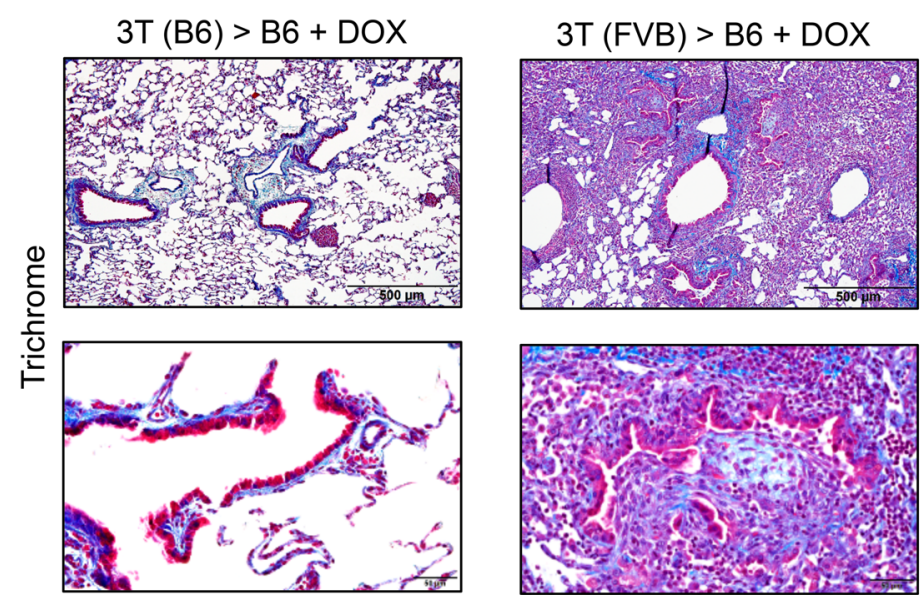

Figure 2. Club cell ablation leads to severe $\mathbf{O B}$ lesions in lung allografts. (A) H\&E histological staining of indicated POD 16 transplants treated with or without DOX and blindly scored for (B) airway inflammation (B score) where 0 $=$ none, $1 R=$ low grade, $2 R$ = high grade, and $X=$ ungradable, and $(C)$ the presence $(1)$ or absence $(0)$ of $O B$ lesions (C score). Dot plots represent mean score \pm SEM of individual data obtained from 5 to 10 transplanted mice per group. (D) Hydroxyproline content and (E) Masson's trichrome staining of indicated transplant tissue at POD 16. Data shown in $\mathbf{D}$ represent mean $\pm \operatorname{SEM}\left(N \geq 4\right.$ /group). ${ }^{* *} P<0.01$, ${ }^{* * *} P<0.001$ by 2 -tailed Mann-Whitney $U$ test. Images in $\mathbf{A}$ and $\mathbf{E}$ are representative histology from at least 5 transplants. Scale bars: $500 \mu \mathrm{m}$ (upper images in both) or $50 \mu \mathrm{m}$ (lower images). 

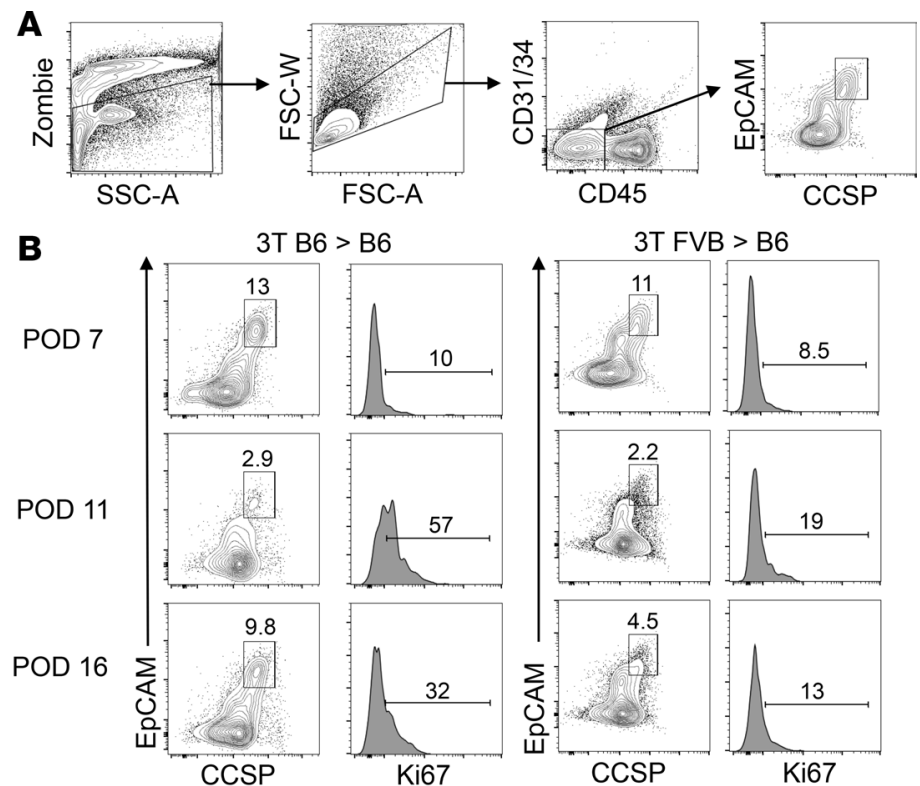
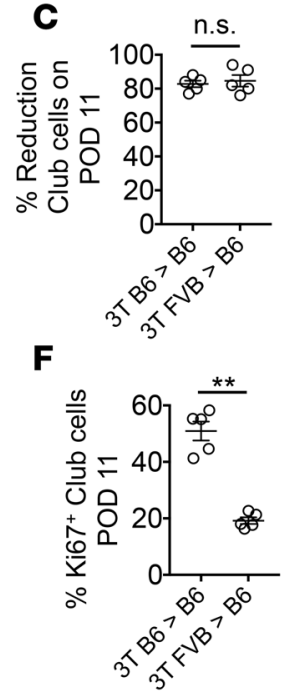

D

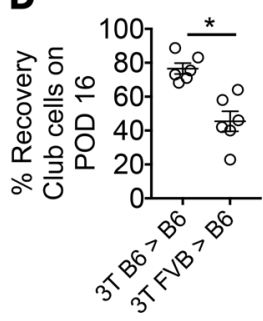

G

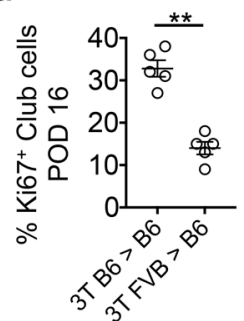

E

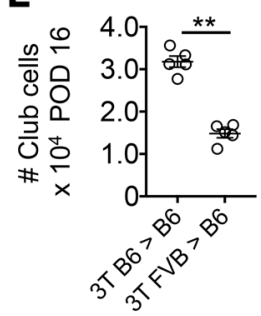

H

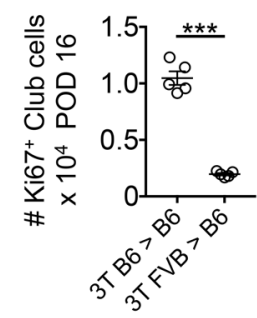

Figure 3. Club cell regenerative responses are suppressed in lung allografts. (A) FACS gating strategy for the identification of club cells. Data shown are contour plots from a 3T FVB donor lung just prior to transplantation. 3T B6 and 3T FVB transplants analyzed at indicated time points and assessed for club cell percentage abundance and proliferation (Ki67). (B) Representative contour blots and histograms from at least 4 transplants. (C) Percentage reduction of club cell abundance assessed on POD 11 calculated relative to levels prior to ablation on POD 7. (D) Percentage recovery of the club cell compartment assessed on POD 16 calculated relative to levels prior to ablation on POD 7. (E) Total number of intragraft club cells on POD 16. Club cell proliferation is shown as percentage abundance on (F) POD 11, (G) POD 16, or as a total number on (H) POD 16. Dot plots represent mean \pm SEM ( $N \geq 4$ /group). n.s., not significant. ${ }^{*} P<0.05$, ${ }^{* *} P<$ $0.01,{ }^{* *} P<0.001$ by 2 -tailed Mann-Whitney $U$ test.

Given CCSP expression within epithelial progenitor pools, the latter approach allowed us to more precisely monitor the regenerative dynamics of club cells through the use of lineage-specific markers and intracellular CCSP expression $(7,20)$. Irrespective of whether the donor lung was on a B6 or FVB background we observed an average $80 \%$ reduction in club cells 1.5 days after doxycycline ingestion, indicating there was not a strain-specific induction of bronchiolar epithelial injury. Another approach to ablate club cells is through the systemic administration of naphthalene, which causes the production of cytotoxic metabolites via oxidation by cytochrome P450 2F2, a monooxygenase that is expressed in club cells (28). Naphthalene administration to our model was ineffective at producing OB lesions. Although the reasons for this are not clear, it has been reported that toxic naphthalene metabolites generated by the liver inhibit 
A

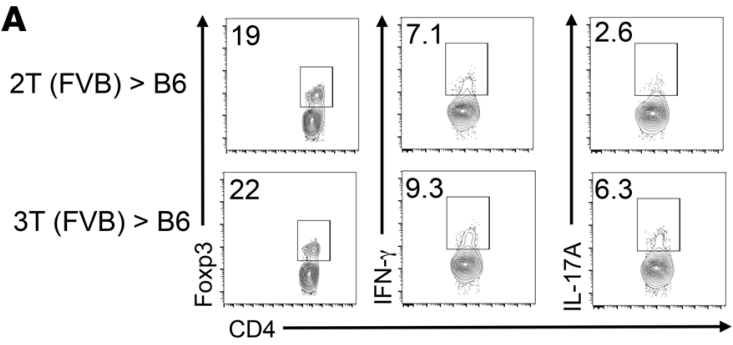

B

$2 \mathrm{~T}(\mathrm{FVB})>\mathrm{B} 6$ O $3 T(F V B)>B 6$
T cells
Foxp3
CD4

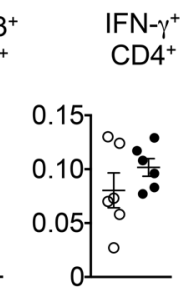

IFN- $\gamma^{+}$
$\mathrm{CD}^{+}$

$\mathrm{IL}-17 \mathrm{~A}^{+}$

$\mathrm{CD} 4^{+}$

IFN- $\gamma^{+}$
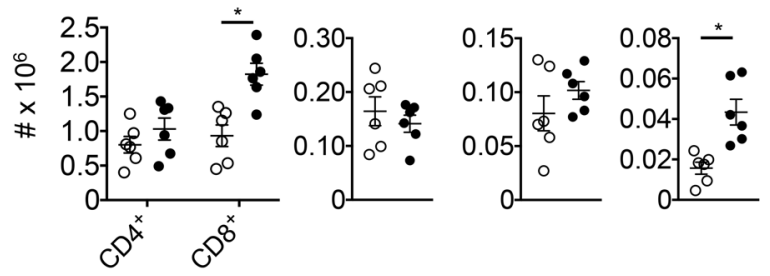

0.20
0.15
0.10
0.05
C

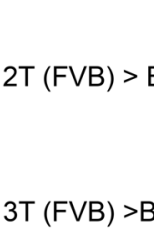

|艹

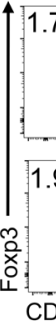

DSA

D
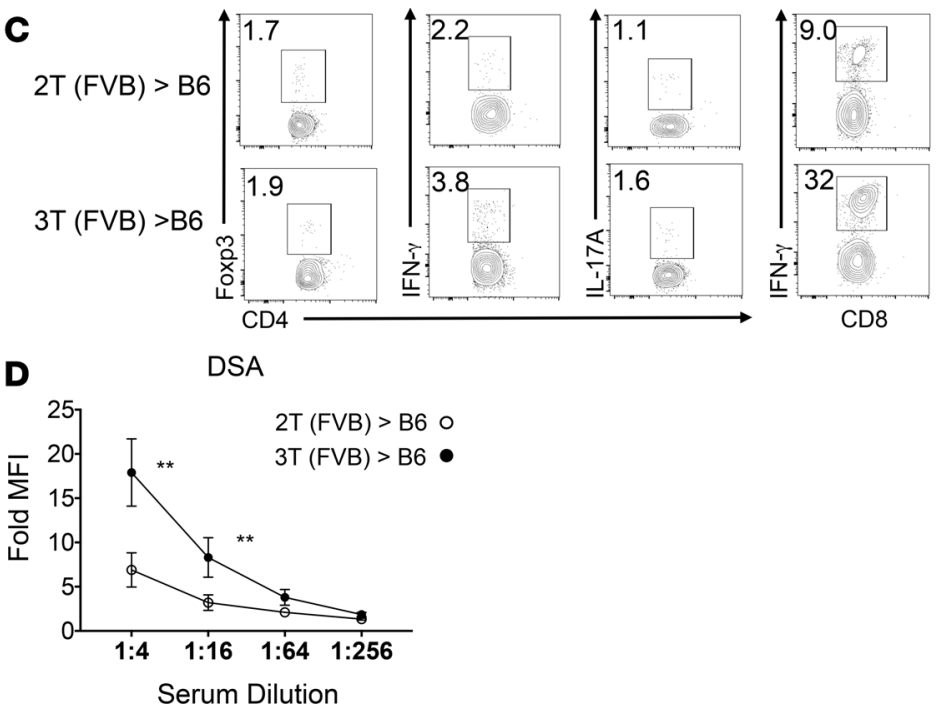

Figure 4. Club cell ablation promotes intragraft effector T cell accumulation and DSA. B6 recipients of $2 T$ FVB and 3T FVB allografts that received DOX were analyzed by FACS on POD 16 for indicated intragraft T lymphocytes. (A) Representative contour plots showing percentage abundance of graft-infiltrating effector T cells from B. (B) T lymphocyte numbers are shown for each transplant and as a mean per group \pm SEM ( $N=6$ /group). ${ }^{*} P<0.05$ by 2 -tailed Mann-Whitney $U$ test. (C) Percentage abundance of airway-infiltrating effector $T$ cells. Contour plots are a representative result from 3 transplants per group. (D) POD 16 recipient serum from $2 T$ and $3 T$ FVB recipients was coincubated with FVB thymocytes at indicated dilution ratios and assessed for DSA with anti-mouse IgM antibodies. Reactivity is shown as fold mean fluorescence intensity (MFI) relative to serum reactivity to syngeneic B6 thymocytes. Each data point represents a mean from at least 4 recipients per group \pm SEM. ${ }^{* *} P<0.01$ by 2 -tailed Mann-Whitney $U$ test.

Ab production by plasma cells (19). Of note, in a new mouse OLT model of lymphocytic bronchitis, B cell deficiency protected allografts from club cell loss (29). Given that we observed DSA generation in our model, these observations collectively raise the possibility that naphthalene prevents a B cell-dependent response that promotes OB. Nevertheless, similar to reports of naphthalene-mediated club cell depletion, we observed the transient spreading of ciliated cells around denuded bronchioles and the retention of a population of injury-resistant club cells with high proliferative capacity $(20,30)$. This was most evident in the high number of proliferating club cells within transplants approximately 2 days after injury induction. Moreover, the relative abundance of proliferating club cells was nearly 3-fold lower in allografts when compared with syngeneic grafts, indicating there is a critical threshold of regenerative capacity required to adequately repair the bronchiolar epithelium. 


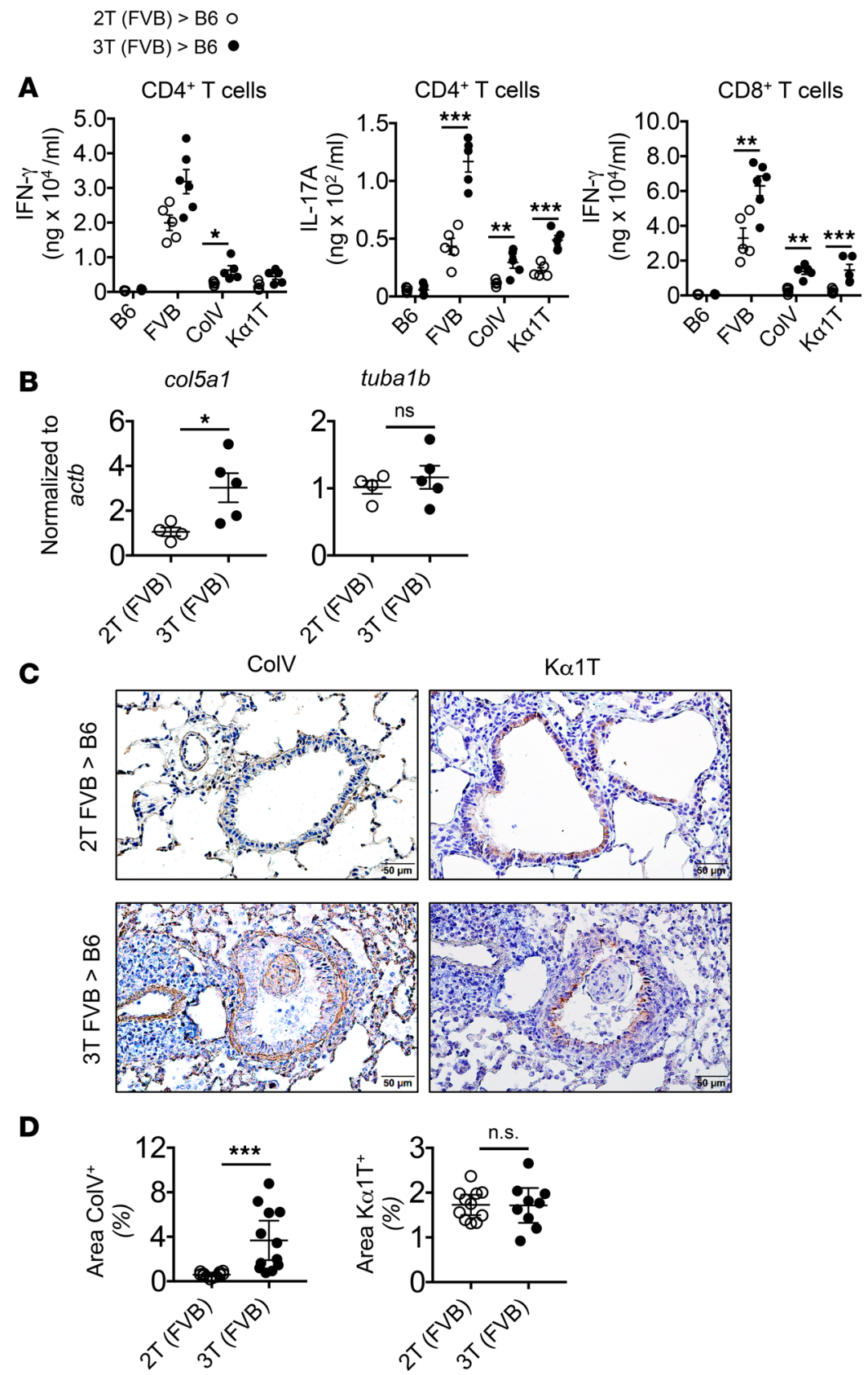

Figure 5. Loss of allogeneic and pulmonary self-antigen tolerance following club cell ablation. (A) POD 16 intragraft $\mathrm{CD}^{+}$and $\mathrm{CD} 8^{+} \mathrm{T}$ cell recall assays for syngeneic (B6) APCs, allogeneic (FVB) APCs, and syngeneic APCs that bear K $\alpha 1 T$ or ColV peptides as measured by IFN- $\gamma$ and IL-17A production. Data points shown are responses from individual transplants and means per group \pm SEM ( $N \geq 5$ /group). (B) Semiquantitative RT-PCR measurements of intragraft ColV (Col5a1) and Ka1T (Tuba1b) mRNA shown normalized to $\beta$-actin (Actb). Each data point represents a single transplant along with a group mean \pm SEM ( $N=5$ /group). ${ }^{*} P<0.05$, ${ }^{* *} P<0.01$, ${ }^{* *} P<0.001$ by 2 -tailed Mann-Whitney $U$ test (A and B). Representative ( $N \geq 3$ /group ) POD 16 allograft CoIV and Ka1T (C) immunochemistry and (D) expression quantitation by staining area. In $\mathbf{D}$, each histogram represents individual measurements from 3 or 4 randomly selected areas enriched for bronchioles for at least 3 transplants along with a mean per group \pm SEM. ${ }^{* *} P<0.001$ by 2 -tailed $t$ test.

Club cell depletion led to the rapid loss of transplant-antigen-specific tolerance. The precise reasons for this observation remain unclear. Interestingly, Stripp and colleagues have shown that mice lacking CCSP expression have elevated Toll-like receptor 4 expression in pulmonary macrophages (31), suggesting that club cells could also play a regulatory role in preventing innate immune responses within lung transplants. Additionally, we observed a striking similarity between the pattern of adaptive immune responses following club cell ablation and clinical reports of lung transplant recipients with BOS. This included the augmentation of 

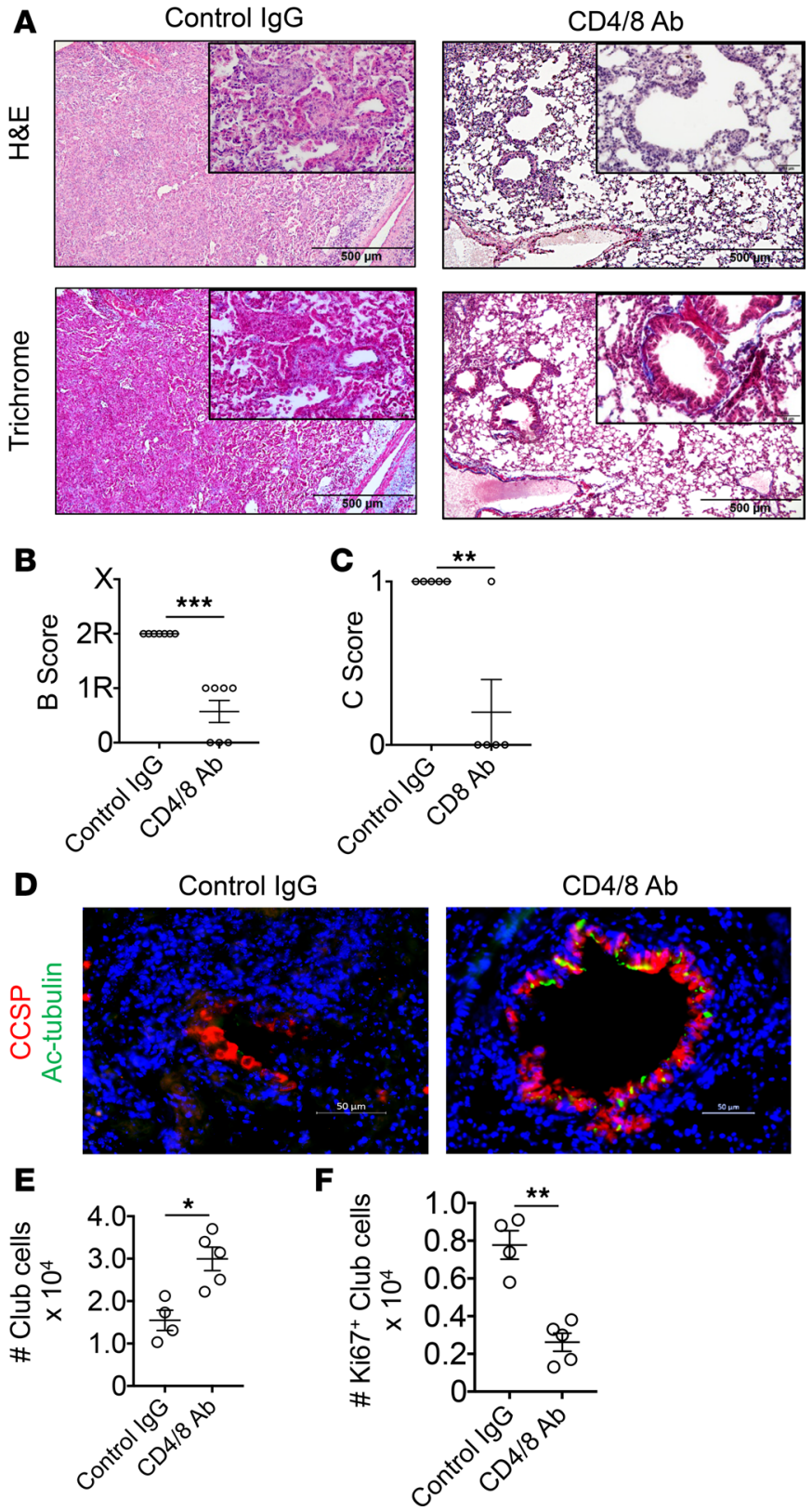

Figure 6. Pan-T cell depletion inhibits $\mathrm{OB}$ and promotes club cell regenerative responses. $3 T \mathrm{FVB} \rightarrow \mathrm{B} 6$ recipients that underwent club cell depletion received either control Ig or CD4- and CD8-depleting Abs on POD 6 and POD 11 were analyzed on POD 16 for bronchiole injury by (A) H\&E and Masson's trichrome stain, (B) airway inflammation, and (C) OB lesion score, or evaluated by immunohistochemistry for (D) bronchiolar epithelial repair with CCSP and Ac-tubulin Abs. Transplant club cell (E) total numbers and (F) proliferating numbers (Ki67+) on POD 16. Results shown in $\mathbf{A}$ are representative stains used for grading in $\mathbf{B}$ and $\mathbf{C}$, which show mean scores \pm SEM ( $N=7 / g r o u p)$. The insets in $\mathbf{A}$ are $\times 400$ (original magnification). Scale bars: $500 \mu \mathrm{m}$ (A) and $50 \mu \mathrm{m}$ (D). Stains shown in $\mathbf{D}$ are representative of 7 transplants and $\mathbf{E}$ and $\mathbf{F}$ show mean numbers \pm SEM $\left(N \geq 4\right.$ /group). ${ }^{*} P<0.05$, ${ }^{* *} P<0.01,{ }^{* * *} P<0.01$ by 2 -tailed Mann-Whitney $U$ test.

Th17-mediated immunity (24), the enhanced recognition of Ka1T and ColV (23), the development of DSA $(21,22)$, and high numbers of effector $\mathrm{CD} 8^{+} \mathrm{T}$ cells in the airway $(32,33)$. We also made insights into effector $\mathrm{T}$ cell activation during $\mathrm{OB}$ development. To the best of our knowledge, this is the first report of the existence of KalT- and ColV-specific effector $\mathrm{CD} 8^{+} \mathrm{T}$ cells in lung allografts. We also observed that increases in intragraft IL-17A ${ }^{+} \mathrm{CD} 4^{+} \mathrm{T}$ cells occur without significant changes in the overall number of graft-resident $\mathrm{CD} 4^{+} \mathrm{T}$ cells. This finding suggests possible de novo generation of Th17 cells within graft tissue through the recruitment of an uncommitted or naive $\mathrm{CD} 4^{+} \mathrm{T}$ cell pool. We have previously demonstrated that the targeted depletion of lung allograft-resident Foxp $3^{+} \mathrm{CD} 4^{+} \mathrm{T}$ cells abrogates established tolerance (34). Recent reports have 

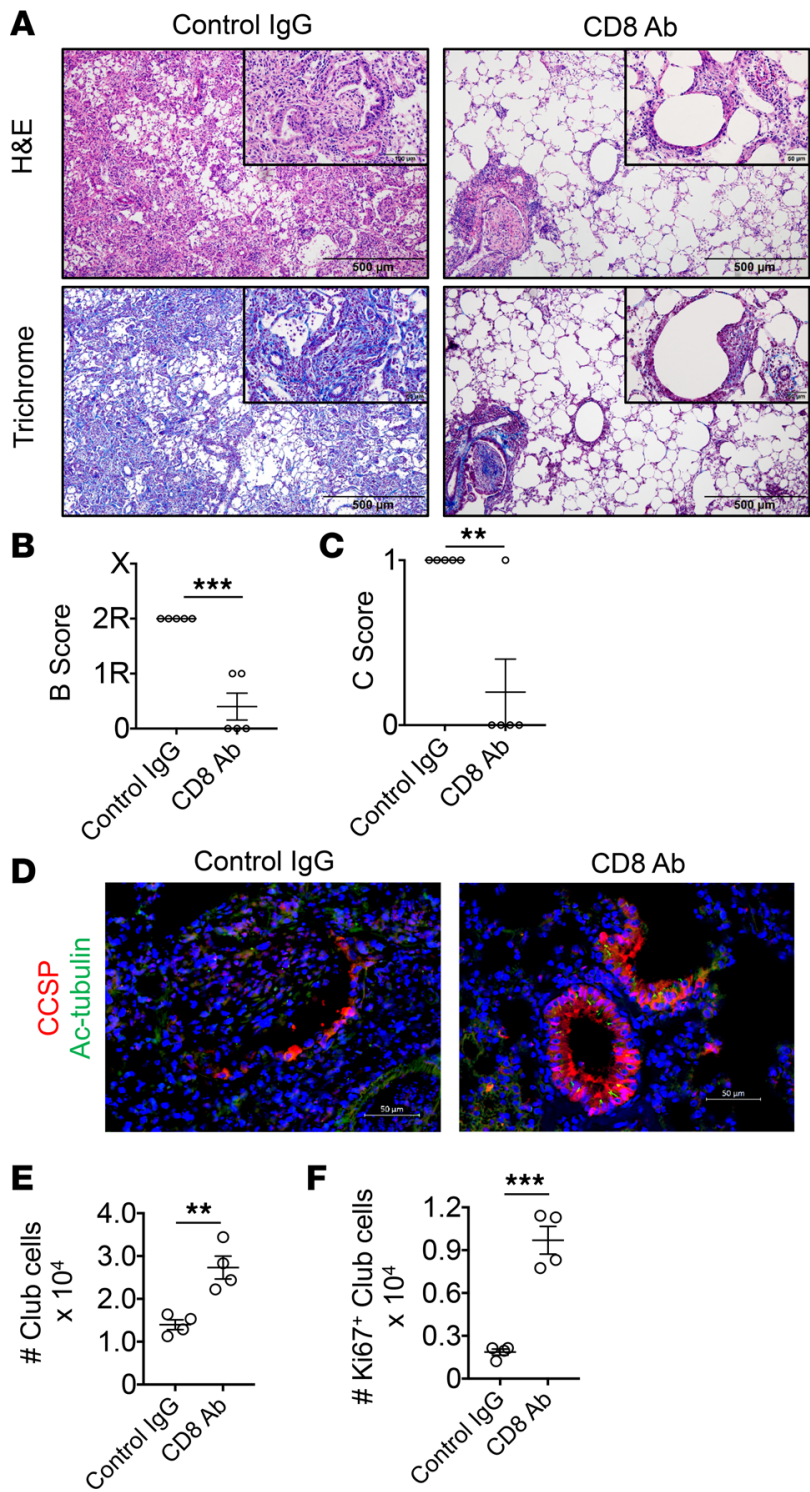

Figure 7. $\mathrm{CD8}^{+} \mathbf{T}$ cell depletion inhibits $\mathrm{OB}$ and promotes club cell regenerative responses. $3 T \mathrm{FVB} \rightarrow \mathrm{B} 6$ recipients that underwent club cell depletion received either control IgG or CD8-depleting Abs on POD 6 and POD 11 and were analyzed on POD 16 for transplant bronchiole injury by (A) H\&E and Masson's trichrome stain, (B) airway inflammation, and (C) OB lesion score, or evaluated by immunohistochemistry for (D) bronchiolar epithelial repair with CCSP and Ac-tubulin Abs. Transplant club cell (E) total numbers and (F) proliferating numbers (Ki67+) on POD 16. Results shown in $\mathbf{A}$ are representative stains used for grading in $\mathbf{B}$ and $\mathbf{C}$, which show mean scores \pm SEM ( $N=5 /$ group). The insets in $\mathbf{A}$ are $\times 400$ (original magnification). Scale bars: $500 \mu \mathrm{m}(\mathbf{A})$ and $50 \mu \mathrm{m}$ (D and insets in $\mathbf{A})$. Stains shown in $\mathbf{D}$ are representative of 5 transplants and $\mathbf{E}$ and $\mathbf{F}$ show mean numbers $\pm \operatorname{SEM}\left(N=4 /\right.$ group). ${ }^{* *} P<0.01,{ }^{* * *} P<0.01$ by 2-tailed Mann-Whitney $U$ test.

also linked the loss of peripheral blood Foxp $3^{+} \mathrm{CD} 4^{+} \mathrm{T}$ cells with increased risk for $\operatorname{CLAD}(35,36)$. Although we did not quantitate peripheral circulating Foxp $3^{+} \mathrm{CD}^{+} \mathrm{T}$ cells, there was no significant change in absolute numbers within graft tissues. One explanation for this discordant observation is that the ratio of Foxp $3^{+} \mathrm{CD} 4^{+}$ $\mathrm{T}$ cells to $\mathrm{T}$ cell effectors may be a more informative measure than is the assessment of absolute numbers (37). Indeed, due to increased $\mathrm{Th} 17$ and effector $\mathrm{CD} 8^{+} \mathrm{T}$ cell numbers, this ratio was sharply lower in allografts with OB. The development of Foxp $3^{+} \mathrm{CD} 4^{+} \mathrm{T}$ cell regulatory dysfunction may also play an important role in allograft rejection (38). Thus, future studies will be required to better understand the role of Foxp $3^{+} \mathrm{CD} 4^{+} \mathrm{T}$ cell abundance and function in OB pathogenesis.

Club cell ablation promoted elevated ColV mRNA and protein expression, which was especially evident within the epithelial basement membranes and OB lesions. Of note, IL-17 has been previously 


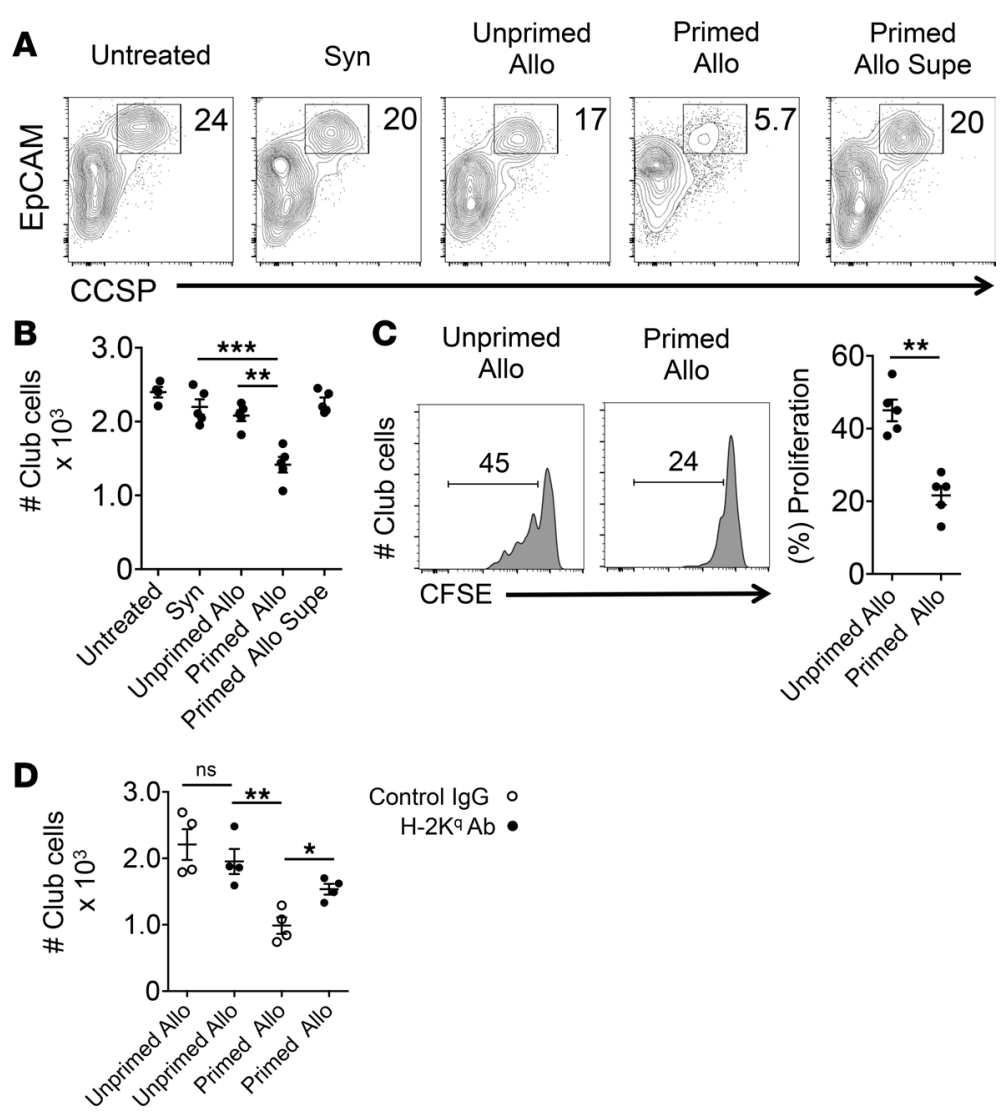

Figure 8. Alloantigen-primed effector CD8 ${ }^{+}$T cells inhibit club cell maintenance and proliferation. Club cells isolated by lineage-negative enrichment from FVB lungs were cocultured without (Untreated) or with either unactivated syngeneic FVB (Syn), unactivated allogeneic B6 (Unprimed Allo) or alloantigen-primed B6 (Primed Allo) CD8 ${ }^{+}$T cells, or with supernatant from alloantigen-primed B6 $\mathrm{CD} 8^{+} \mathrm{T}$ cells (Primed Allo Supe). Thirty-six hours later, club cell abundance was analyzed and shown as (A) representative contour plots from at least 4 independent experiments, or (B) total numbers per experiment with a group mean \pm SEM ( $N \geq 4$ /group). Club cells analyzed for proliferation in the presence of indicated CD8 ${ }^{+} T$ cells by (C) CFSE dilution shown as a representative histogram from 5 independent experiments along with a group mean \pm SEM. ${ }^{* *} P<0.01,{ }^{* *} P<0.001$ by 2 -tailed Mann-Whitney $U$ test (B and $\mathbf{C}$ ). (D) Club cell numbers remaining after coculture with indicated $\mathrm{CD} 8^{+} \mathrm{T}$ cells in the presence of control IgC or a neutralizing antibody directed against the $\mathrm{H}-2 \mathrm{~K}^{q}$ (FVB haplotype) $\mathrm{MHC}$ class I protein. Each data point represents a single determination from 4 independent experiments with a group mean \pm SEM. ${ }^{*} P<0.05$, ${ }^{* *} P<0.01$ by unpaired 2 -tailed $t$ test.

reported to promote ColV overexpression and the development of OB (39). In line with this previous observation we demonstrated that $\mathrm{CD} 4^{+} \mathrm{T}$ cells isolated from allografts with $\mathrm{OB}$ made significantly more IL-17A when challenged with ColV peptides when compared with $\mathrm{CD}^{+} \mathrm{T}$ cells isolated from tolerant allografts. Despite increased T cell-mediated recognition of Ka1T we did not detect changes in its expression following club cell ablation. One possible reason for these differences comes from a recent finding that $\mathrm{K} \alpha 1 \mathrm{~T}$ protein is highly enriched within exosomes released from human solid organ allografts, including chronically rejected lung transplants (40). As exosome protein cargo can be endocytosed and presented by dendritic cells (41), it remains plausible that $\mathrm{T}$ cells can be primed for recognition of Ka1T without increased evidence of expression within parenchymal tissues.

In our model we used a well-established costimulatory blockade regimen $(16,42,43)$ to induce lung allograft tolerance, which interrupts both CD154/CD40 and B7/CD28 signaling in T cells. CD154 antagonism has recognized toxicity in humans due to CD154 expression on activated platelets (44). Also, in a mouse heterotopic heart allograft model, the reported mechanism by which costimulatory blockade induces acceptance is through the deletion of alloreactive $\mathrm{T}$ cells (45). In contrast, calcineurin inhibitors are thought to promote tolerance by largely inhibiting $\mathrm{T}$ cell activation (46). These observations suggest that the use of costimulatory blockade limits the clinical relevance of our model. However, OB lesions have been reported to form spontaneously in about half of BALB/c $\rightarrow$ B6 orthotopic lung transplant recipients immunosuppressed with cyclosporine and steroids at between 1 and 3 months after engraftment (47). 
Moreover, despite the use of costimulatory blockade, we could readily detect intragraft alloreactive T cells in $2 \mathrm{~T} \mathrm{FVB}$ recipients, suggesting such clones are not efficiently deleted in lung transplants.

How $\mathrm{T}$ cells regulate epithelial cell repair in lung transplants remains an understudied area. This is likely due to observations that several $\mathrm{CD}^{+}$and $\mathrm{CD}^{+} \mathrm{T}$ cell subsets are required for the induction of immunosuppression-mediated lung allograft tolerance $(16,42,43)$. Accordingly, we chose to deplete $\mathrm{T}$ cells using Abs after the establishment of tolerance (16), but just prior to the induction of epithelial injury to study club cell responses. We observed that pan-T cell depletion largely reversed the loss of proliferating club cells, restored the club cell compartment, and largely eliminated OB lesions. However, we still noted some epithelial inflammation conceivably caused by the homeostatic expansion of residual intragraft alloreactive $\mathrm{T}$ cells (48). We extended these studies to determine whether $\mathrm{CD}^{+}$or $\mathrm{CD} 4^{+} \mathrm{T}$ cells promote $\mathrm{OB}$ generation. $\mathrm{CD}^{+}$ $\mathrm{T}$ cell depletion led to the promotion of club cell regenerative responses and protection from $\mathrm{OB}$ that was comparable to pan-T cell depletion. In contrast, $\mathrm{CD}^{+} \mathrm{T}$ cell depletion had no effect on OB lesion development, possibly due to the elimination of regulatory $\mathrm{CD} 4^{+} \mathrm{T}$ cells, which are reported to inhibit effector $\mathrm{CD} 8^{+}$ $\mathrm{T}$ cell function in allografts $(49,50)$. We further explored the role of $\mathrm{CD} 8^{+} \mathrm{T}$ cells in $\mathrm{OB}$ by coculturing $\mathrm{CD} 8^{+}$ $\mathrm{T}$ cells with club cells. Consistent with our observations of high numbers of airway-resident effector $\mathrm{CD} 8^{+}$ $\mathrm{T}$ cells in lung allografts with $\mathrm{OB}$, alloantigen-primed $\mathrm{CD}^{+} \mathrm{T}$ cells inhibited club cell maintenance and proliferation. Additionally, in line with previous findings that airway-resident allogeneic $\mathrm{CD} 8^{+} \mathrm{T}$ cells recognize apical MHC class I expressed on airway epithelium (26), we observed that neutralizing Abs against $\mathrm{H}-2 \mathrm{~K}^{\mathrm{q}}$ improved club cell maintenance. Whether alloantigen-primed $\mathrm{CD} 8^{+} \mathrm{T}$ cells kill or suppress the proliferation of club cells was not directly addressed by our studies, but is the subject of future investigation.

In summary, using a model of OLT we find that club cell ablation leads to development of OB and the induction of adaptive immune responses associated with BOS risk. Given that severe and reliable OB lesions are generated within 16 days after transplantation, this model should be useful for screening potential approaches to treating bronchiolar epithelial injury. To that end, our studies advocate for further defining $\mathrm{T}$ cell-dependent pathways that affect club cell regeneration and differentiation to identify new therapeutic targets for the prevention of BOS.

\section{Methods}

Mice and OLT. C57BL/6 (B6) and FVB/N (FVB) were purchased from Jackson Laboratories. CCSP rtTA/ TetOCre/DT-A (3T) mice were gifts from Jeffery Whitsett of The Children's Hospital of Cincinnati. 3T mice were backcrossed to greater than $99 \%$ FVB and C57BL/6 backgrounds, which was confirmed using microsatellite-assisted accelerated backcrossing (MAX-BAX, Charles River). Mouse left OLT was conducted with 8- to 12-week-old donor and recipient mice as previously described by our group (42). To induce allograft acceptance, recipients received i.p. $250 \mu \mathrm{g}$ of CD40L Abs (MR1) on POD 0 and $200 \mu \mathrm{g}$ of mouse recombinant CTLA4Ig on POD 2 (16).

Club cell ablation and T cell depletion. Club cell injury was triggered by doxycycline ingestion via food (625 $\mathrm{mg} / \mathrm{kg}$ chow, ENVIGO) and water ( $2 \mathrm{mg} / \mathrm{ml}$, Sigma-Aldrich) from POD 7 to POD 9.5. T lymphocyte cell depletion was accomplished by i.p. injection of anti-CD4 (500 $\mu \mathrm{g}$ GK1.5; Bio X Cell) or anti-CD8 (500 $\mu \mathrm{g}$, 53-6.7, Bio-X-Cell) Abs or by using both aforementioned Abs for pan-T cell depletion. We used rat IgG2b (clone LTF-2; Bio-X-Cell), rat IgG2a (clone 2A3; Bio-X-Cell), or both Abs for isotype controls for CD4 ${ }^{+}$, $\mathrm{CD}^{+}$, or pan-T depletion, respectively. Abs were administered on POD 6 and 11.

Histological analysis. Harvested grafts were formaldehyde fixed, paraffin embedded, and stained with $\mathrm{H} \& \mathrm{E}$ or Masson's trichrome stain. Lung transplant histology was graded by a blinded pathologist using the 2007 revision of the 1996 working formulation for the standardization of nomenclature in the diagnosis of lung rejection, where small-airway inflammation is scored Grade B0 (none), Grade B1R (low grade), Grade B2R (high grade), and BX (ungradable). OB is graded without regard to inflammation as C1 (present) or C0 (absent) (51).

Bronchiolar epithelium paraffin sections were first blocked with $5 \%$ goat serum and $2 \%$ fish gelatin (both from Sigma-Aldrich) at $25^{\circ} \mathrm{C}$ for 45 minutes. Sections were then stained with 1:500 polyclonal rabbit anti-mouse/rat CCSP (Seven Hills Bioreagents) and mouse anti-Ac-tubulin, 1:5000 (6-11B-1, Sigma-A1drich) overnight at $4^{\circ} \mathrm{C}$. For immunofluorescent visualization, we used goat anti-mouse Alexa Fluor 488labeled secondary Ab, 1:1000 (Thermo Fisher Scientific) and goat anti-rabbit Alexa Fluor 555-labeled secondary Ab, 1:1000 (Cell Signaling Technology). For ColV and Ka1T immunohistological analysis 1:100 polyclonal rabbit anti-ColV (Abcam), 1:200 polyclonal rabbit anti-Ka1T (Thermo Fisher Scientific), 
or polyclonal rabbit IgG Isotype (Abcam) Ab dilutions were used in conjunction with a Vectastain Elite System kit (LS Bio) for detection in accordance with the manufacturer's recommendations. Quantitation of stain was conducted with ImageJ bundled with Java version 1.8.0 (NIH) in which total pixels of stain were assessed outside nuclear areas. For intragraft collagen measurements we used a Hydroxyproline Assay Kit (Sigma-Aldrich) in accordance with manufacturer's recommendations. Briefly, lung tissue was extracted for protein with $6.0 \mathrm{~N} \mathrm{HCl}$ for 3 hours at $120^{\circ} \mathrm{C}$ and then dried at $60^{\circ} \mathrm{C}$ overnight. Then, $10 \mu \mathrm{g}$ of protein was assayed for reactivity for oxidized hydroxyproline with 4-(dimethylamino) benzaldehyde, which in turn generates colorimetric product that was read by absorbance at $560 \mathrm{~nm}$ on a BioTek Synergy HTX Microplate Analyzer.

Flow cytometric analysis and antigen recall assays. Lung tissue was minced and digested in RPMI 1640 with type 2 collagenase $(0.5 \mathrm{mg} / \mathrm{ml})$ (Worthington Biochemical) and 5 units $/ \mathrm{ml}$ DNAse (Sigma-Aldrich) for 90 minutes at $37^{\circ} \mathrm{C}$ and then filtered through a $70-\mu \mathrm{m}$ cell strainer (Thermo Fisher Scientific) and treated with ACK lysing buffer (Worthington Biochemical). Live cell discrimination was conducted with the Zombie (Biolegend) fixable dye. Cell surface staining was conducted with the following Abs: CD45 (30-F11, eBioscience), CD45.2 (104, Biolegend), CD90.2 (53-2.1, eBioscience), CD4 (clone RM4-5, eBioscience), CD8a (53-6.7, eBioscience), CD31 (390, Biolegend), CD34 (HM34, Biolegend), and CD326 (G8.8, Biolegend). Staining for Foxp3 (FJK-16s, eBioscience), Ki-67 (16A8, Biolegend), and polyclonal rabbit anti-mouse CCSP (Seven Hills Bioreagents, catalog WRAB-3950) was conducted with an intranuclear Transcription Factor Staining Buffer Kit (Invitrogen) in accordance with the manufacturer's recommendations. For IFN- $\gamma$ and IL-17A expression, cells were first stimulated with $1 \mu \mathrm{M}$ ionomycin (Sigma-Aldrich) and $20 \mathrm{ng} / \mathrm{ml}$ PMA (Sigma-Aldrich) for 3.5 hours with $2 \mu \mathrm{M}$ Golgi Plug (BD Biosciences) added for the last 3 hours of stimulation and stained with anti-IFN- $\gamma$ (XMG1.2, eBioscience) and anti-IL-17A (TC11-18H10.1, Biolegend) using a Cytofix/Cytoperm kit (BD Biosciences) in accordance with the manufacturer's recommendations. For antigen specificity measurements, $\mathrm{T}$ cells were fractionated by positive selection using $\mathrm{CD}^{+}$or $\mathrm{CD}^{+}$immunomagnetic bead labeling kits (Miltenyi Biotec) from allograft cell suspensions and cocultured at a 3:1 ratio with irradiated T cell-depleted FVB or B6 cell splenocytes for 96 hours pulsed with $0.5 \mu \mathrm{g} / \mathrm{ml}$ K $\alpha 1 \mathrm{~T}$ and ColV (obtained from T. Mohannakumar, St. Joseph's Hospital, Phoenix, Arizona, USA). IFN- $\gamma$ and IL-17A were measured with uncoated ELISA kits from Invitrogen in accordance with the manufacturer's recommendations.

Semiquantitative RT-PCR. Lung tissues were extracted for RNA with an RNAeasy kit (Qiagen) and reverse transcribed with the High-Capacity cDNA Reverse Transcription Kit (Thermo Fisher Scientific). Transcripts were semiquantified with PrimePCR Syber Green Assay (Bio-Rad) kits for Col5a1 (qMmuCED0046279), Tubalb (qMmuCED0040564), and Atcb (qMmuCED0027505) in accordance with the manufacturer's recommendations.

Club cell enrichment and culture with $C D 8^{+} T$ cells. FVB lung tissue cell isolates were prepared as described for FACS preparation and incubated with biotin-conjugated Abs (all from eBioscience) specific for CD45.1 (clone A20), CD34 (clone RAM34), CD31 (clone MEC13.3), CD90.1 (clone HIS51), and CD15 (clone mc-480), washed, and then labeled with anti-biotin MicroBeads (Miltenyi Biotec) for negative selection on LS columns (Miltenyi Biotec). Remaining cells were then incubated with biotin-conjugated CD326 Abs (clone caa7-9G8, Miltenyi Biotec), washed, and then labeled anti-biotin MicroBeads for positive selection on an MS column (Miltenyi Biotec). Enriched club cell fractions were resuspended in MTEC/Plus medium (52) and seeded at $3.3 \times 10^{4}$ cells per well in flat-bottom 96-well tissue culture plates (Thermo Fisher Scientific) coated with $50 \mu \mathrm{g} / \mathrm{ml}$ type I rat tail collagen (Becton Dickinson). For proliferation analysis, club cells were stained with $10 \mu \mathrm{M}$ CFSE (Thermo Fisher Scientific) prior to seeding. CD8 ${ }^{+} \mathrm{T}$ cells were isolated from B6 or FVB resting mouse spleens using $\mathrm{CD}^{+}$immunomagnetic bead labeling kits (Miltenyi Biotec) in accordance with the manufacturer's recommendations. To prime $\mathrm{CD} 8^{+} \mathrm{T}$ cells with alloantigen, $\mathrm{T}$ cell-depleted CD45.1 $1^{+}$ FVB splenocytes were cocultured with $\mathrm{B} 6 \mathrm{CD} 8^{+} \mathrm{T}$ cells at a 3 to 1 respective ratio with $100 \mathrm{ng} / \mathrm{ml}$ LPS for 72 hours, which was used to augment alloantigen presentation. Alloantigen-primed $\mathrm{CD}^{+} \mathrm{T}$ cells were removed from cultures by using immunomagnetic bead positive selection conducted with biotin-conjugated CD45.2 Abs (clone A20, eBioscience), anti-biotin MicroBeads, and LS columns. CD8 $8^{+} \mathrm{T}$ cells $\left(1 \times 10^{5}\right)$ were added to each club cell culture well for 24 hours. For proliferation analysis, $\mathrm{CD} 8^{+} \mathrm{T}$ cells were cocultured with CFSE-labeled club cells for 36 hours. Four or 5 wells were used for each test condition. For MHC class I blockade experiments $10 \mu \mathrm{g} / \mathrm{ml}$ of neutralizing Abs against $\mathrm{H}-2 \mathrm{~K}^{\mathrm{q}}$ (clone Y-3, Bio-X-Cell) or IgG2b isotype control (clone MPC-11, Bio-X-Cell) was added to cultures 1 hour prior to the placement of $\mathrm{CD}^{+} \mathrm{T}$ cells. 
Club cells were released from plates using 0.05\% trypsin (Thermo Fisher Scientific), washed, and then analyzed on a Zombie ${ }^{-} \mathrm{CD} 45^{-} \mathrm{CD} 31^{-} \mathrm{CD} 34^{-} \mathrm{CD} 326^{+} \mathrm{CCSP}^{+}$gate using Countbright beads (Thermo Fisher Scientific) for quantitative FACS analysis.

Statistics. Unless indicated, a 2-tailed Mann-Whitney $U$ test was performed to assess statistical relevance using GraphPad Prism version 7.0. $P<0.05$ was considered significant. n.s., not significant.

Study approval. Animal experiments were conducted in accordance with an approved Washington University Animal Care and Use Committee protocol (number 20160212).

\section{Author contributions}

AEG, ZL, HJH, AKTP, JMG, and SLB designed the experiments. AEG, HJH, and AKTP conceptualized the model design. ZL, DS, MC, DLC, and HJH executed T cell studies. ZL performed immunohistochemical staining, developed the club cell assays, and made figures. FL performed the mouse orthotopic lung transplants. YF conducted the donor-specific antibody analysis. KNP validated and monitored the HLA haplotypes of the triple-transgenic donor strains. AEG, ZL, RH, DK, ASK, and SLB wrote and edited the manuscript.

\section{Acknowledgments}

We thank Jihong Zhu for her excellent technical assistance. We also thank John H. Ritter for the analysis of graft pathology. This work was supported by a Cystic Fibrosis Foundation research grant and by NIH grants P01AI116501-01, R21AI119506, R01HL121218-01, and 2RHL094601.

Address correspondence to: Andrew E. Gelman, Maritz Professor of Immunology \& Oncology, Campus Box 8234, 660 South Euclid Avenue, Washington University in St. Louis, St. Louis, Missouri 63110-1013, USA. Phone: 314.362.8382; Email: gelmana@wudosis.wustl.edu.

1. Yusen RD, et al. The Registry of the International Society for Heart and Lung Transplantation: Thirty-third Adult Lung and Heart-Lung Transplant Report-2016; Focus theme: Primary diagnostic indications for transplant. J Heart Lung Transplant. 2016;35(10):1170-1184.

2. Verleden SE, Sacreas A, Vos R, Vanaudenaerde BM, Verleden GM. Advances in understanding bronchiolitis obliterans after lung transplantation. Chest. 2016;150(1):219-225.

3. Rokicki W, Rokicki M, Wojtacha J, Dżeljijli A. The role and importance of club cells (Clara cells) in the pathogenesis of some respiratory diseases. Kardiochir Torakochirurgia Pol. 2016;13(1):26-30.

4. Dierynck I, Bernard A, Roels H, De Ley M. Potent inhibition of both human interferon-gamma production and biologic activity by the Clara cell protein CC16. Am J Respir Cell Mol Biol. 1995;12(2):205-210.

5. Montoro DT, et al. A revised airway epithelial hierarchy includes CFTR-expressing ionocytes. Nature. 2018;560(7718):319-324.

6. Perl AK, Riethmacher D, Whitsett JA. Conditional depletion of airway progenitor cells induces peribronchiolar fibrosis. Am J Respir Crit Care Med. 2011;183(4):511-521.

7. Teisanu RM, et al. Functional analysis of two distinct bronchiolar progenitors during lung injury and repair. Am J Respir Cell Mol Biol. 2011;44(6):794-803.

8. Shah RJ, et al. Early plasma soluble receptor for advanced glycation end-product levels are associated with bronchiolitis obliterans syndrome. Am J Transplant. 2013;13(3):754-759.

9. Borthwick LA, et al. Pseudomonas aeruginosa induced airway epithelial injury drives fibroblast activation: a mechanism in chronic lung allograft dysfunction. Am J Transplant. 2016;16(6):1751-1765.

10. Khalifah AP, et al. Respiratory viral infections are a distinct risk for bronchiolitis obliterans syndrome and death. Am J Respir Crit Care Med. 2004;170(2):181-187.

11. Mertens V, et al. Bile acids aspiration reduces survival in lung transplant recipients with BOS despite azithromycin. Am J Transplant. 2011;11(2):329-335.

12. Neujahr DC, et al. Bile acid aspiration associated with lung chemical profile linked to other biomarkers of injury after lung transplantation. Am J Transplant. 2014;14(4):841-848.

13. Nord M, Schubert K, Cassel TN, Andersson O, Riise GC. Decreased serum and bronchoalveolar lavage levels of Clara cell secretory protein $(\mathrm{CC} 16)$ is associated with bronchiolitis obliterans syndrome and airway neutrophilia in lung transplant recipients. Transplantation. 2002;73(8):1264-1269.

14. Bourdin A, et al. Donor clara cell secretory protein polymorphism is a risk factor for bronchiolitis obliterans syndrome after lung transplantation. Transplantation. 2012;94(6):652-658

15. Kelly FL, et al. Epithelial clara cell injury occurs in bronchiolitis obliterans syndrome after human lung transplantation. Am J Transplant. 2012;12(11):3076-3084.

16. Li W, et al. Lung transplant acceptance is facilitated by early events in the graft and is associated with lymphoid neogenesis. Mucosal Immunol. 2012;5(5):544-554.

17. Müller C, et al. Early extracellular matrix changes are associated with later development of bronchiolitis obliterans syndrome after lung transplantation. BMJ Open Respir Res. 2017;4(1):e000177.

18. Reynolds SD, et al. Conditional clara cell ablation reveals a self-renewing progenitor function of pulmonary neuroendocrine 
cells. Am J Physiol Lung Cell Mol Physiol. 2000;278(6):L1256-L1263.

19. Kawabata TT, White KL. Effects of naphthalene and naphthalene metabolites on the in vitro humoral immune response. $J$ Toxicol Environ Health. 1990;30(1):53-67.

20. Guo L, et al. Generation of induced progenitor-like cells from mature epithelial cells using interrupted reprogramming. Stem Cell Reports. 2017;9(6):1780-1795.

21. Safavi S, Robinson DR, Soresi S, Carby M, Smith JD. De novo donor HLA-specific antibodies predict development of bronchiolitis obliterans syndrome after lung transplantation. J Heart Lung Transplant. 2014;33(12):1273-1281.

22. Morrell MR, et al. De novo donor-specific HLA antibodies are associated with early and high-grade bronchiolitis obliterans syndrome and death after lung transplantation. J Heart Lung Transplant. 2014;33(12):1288-1294.

23. Hachem RR, Tiriveedhi V, Patterson GA, Aloush A, Trulock EP, Mohanakumar T. Antibodies to K- $\alpha 1$ tubulin and collagen V are associated with chronic rejection after lung transplantation. Am J Transplant. 2012;12(8):2164-2171.

24. Burlingham WJ, et al. IL-17-dependent cellular immunity to collagen type V predisposes to obliterative bronchiolitis in human lung transplants. J Clin Invest. 2007;117(11):3498-3506

25. Chen DL, et al. Increased T cell glucose uptake reflects acute rejection in lung grafts. Am J Transplant. 2013;13(10):2540-2549.

26. Kreisel D, et al. Polarized alloantigen presentation by airway epithelial cells contributes to direct $\mathrm{CD} 8^{+} \mathrm{T}$ cell activation in the airway. Am J Respir Cell Mol Biol. 2011;44(6):749-754.

27. Sellers RS, Clifford CB, Treuting PM, Brayton C. Immunological variation between inbred laboratory mouse strains: points to consider in phenotyping genetically immunomodified mice. Vet Pathol. 2012;49(1):32-43.

28. Stripp BR, Maxson K, Mera R, Singh G. Plasticity of airway cell proliferation and gene expression after acute naphthalene injury. Am J Physiol. 1995;269(6 Pt 1):L791-L799.

29. Smirnova NF, et al. Inhibition of B cell-dependent lymphoid follicle formation prevents lymphocytic bronchiolitis after lung transplantation. JCI Insight. 2019;4(3):123971.

30. Guha A, Vasconcelos M, Zhao R, Gower AC, Rajagopal J, Cardoso WV. Analysis of Notch signaling-dependent gene expression in developing airways reveals diversity of Clara cells. PLoS ONE. 2014;9(2):e88848.

31. Snyder JC, Reynolds SD, Hollingsworth JW, Li Z, Kaminski N, Stripp BR. Clara cells attenuate the inflammatory response through regulation of macrophage behavior. Am J Respir Cell Mol Biol. 2010;42(2):161-171.

32. Zheng L, et al. Longitudinal comparisons of lymphocytes and subtypes between airway wall and bronchoalveolar lavage after human lung transplantation. Transplantation. 2005;80(2):185-192.

33. Hodge $\mathrm{S}$, et al. Increased levels of $\mathrm{T}$ cell granzyme $\mathrm{b}$ in bronchiolitis obliterans syndrome are not suppressed adequately by current immunosuppressive regimens. Clin Exp Immunol. 2009;158(2):230-236.

34. Li W, et al. Bronchus-associated lymphoid tissue-resident Foxp3 $3^{+} \mathrm{T}$ lymphocytes prevent antibody-mediated lung rejection. J Clin Invest. 2019;129(2):556-568.

35. Salman J, et al. Association of higher $\mathrm{CD} 4^{+} \mathrm{CD} 25^{\text {high }} \mathrm{CD} 127^{\text {low }}, \mathrm{FoxP}^{+}$, and IL-2 ${ }^{+} \mathrm{T}$ cell frequencies early after lung transplantation with less chronic lung allograft dysfunction at two years. Am J Transplant. 2017;17(6):1637-1648.

36. Piloni D, et al. Analysis of long term $\mathrm{CD} 4^{+} \mathrm{CD} 25^{\text {high }} \mathrm{CD} 127^{-}$T-reg cells kinetics in peripheral blood of lung transplant recipients. BMC Pulm Med. 2017;17(1):102.

37. Chung $\mathrm{BH}$, et al. Clinical significance of the ratio between FOXP3 positive regulatory $\mathrm{T}$ cell and interleukin-17 secreting cell in renal allograft biopsies with acute T-cell-mediated rejection. Immunology. 2012;136(3):344-351.

38. Bagley J, Yuan J, Chandrakar A, Iacomini J. Hyperlipidemia alters regulatory T cell function and promotes resistance to tolerance induction through costimulatory molecule blockade. Am J Transplant. 2015;15(9):2324-2335.

39. Vittal R, et al. IL-17 induces type V collagen overexpression and EMT via TGF- $\beta$-dependent pathways in obliterative bronchiolitis. Am J Physiol Lung Cell Mol Physiol. 2013;304(6):L401-L414.

40. Sharma M, Ravichandran R, Bansal S, Bremner RM, Smith MA, Mohanakumar T. Tissue-associated self-antigens containing exosomes: Role in allograft rejection. Hum Immunol. 2018;79(9):653-658.

41. Morelli AE, et al. Endocytosis, intracellular sorting, and processing of exosomes by dendritic cells. Blood. 2004;104(10):3257-3266

42. Krupnick AS, et al. Central memory CD8 $8^{+} \mathrm{T}$ lymphocytes mediate lung allograft acceptance. J Clin Invest. 2014;124(3):1130-1143.

43. Takahashi T, et al. PD-1 expression on CD8(+) T cells regulates their differentiation within lung allografts and is critical for tolerance induction. Am J Transplant. 2018;18(1):216-225.

44. Henn V, et al. CD40 ligand on activated platelets triggers an inflammatory reaction of endothelial cells. Nature. 1998;391(6667):591-594.

45. Wells $\mathrm{AD}$, et al. Requirement for T-cell apoptosis in the induction of peripheral transplantation tolerance. Nat Med. 1999;5(11):1303-1307.

46. Hermann-Kleiter N, Baier G. NFAT pulls the strings during CD4+ T helper cell effector functions. Blood. 2010;115(15):2989-2997.

47. De Vleeschauwer $\mathrm{S}$, et al. Chronic rejection pathology after orthotopic lung transplantation in mice: the development of a murine BOS model and its drawbacks. PLOS ONE. 2012;7(1):e29802.

48. Moxham VF, et al. Homeostatic proliferation of lymphocytes results in augmented memory-like function and accelerated allograft rejection. J Immunol. 2008;180(6):3910-3918.

49. van Maurik Av, Herber M, Wood KJ, Jones ND. Cutting edge: $C D 4^{+} \mathrm{CD} 25^{+}$alloantigen-specific immunoregulatory cells that can prevent $\mathrm{CD}^{+} \mathrm{T}$ cell-mediated graft rejection: implications for anti-CD154 immunotherapy. J Immunol. 2002;169(10):5401-5404.

50. Lin CY, Graca L, Cobbold SP, Waldmann H. Dominant transplantation tolerance impairs CD8 ${ }^{+} \mathrm{T}$ cell function but not expansion. Nat Immunol. 2002;3(12):1208-1213.

51. Stewart S, et al. Revision of the 1996 working formulation for the standardization of nomenclature in the diagnosis of lung rejection. J Heart Lung Transplant. 2007;26(12):1229-1242.

52. You Y, Richer EJ, Huang T, Brody SL. Growth and differentiation of mouse tracheal epithelial cells: selection of a proliferative population. Am J Physiol Lung Cell Mol Physiol. 2002;283(6):L1315-L1321. 